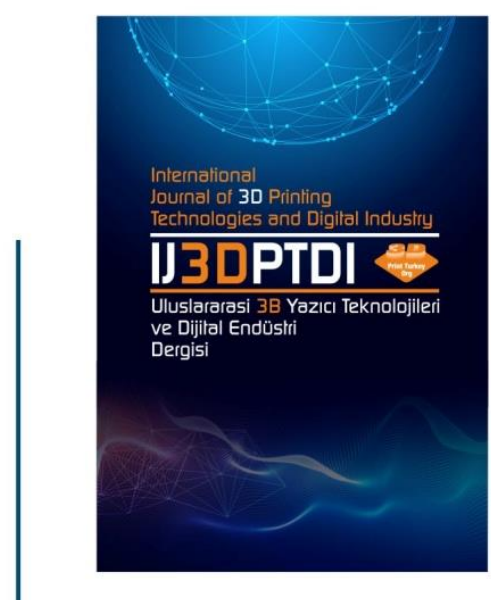

ULUSLARARASI 3B YAZICI TEKNOLOJILERI

VE DIJITAL ENDÜSTRI DERGISI

INTERNATIONAL JQURNAL QF 30 PRINTING TECHNOLOGIES AND DIGITAL INDUSTRY

ISSN:2602-3350 [Online]

URL: https://dergipark.org.tr/ij3dptdi

\title{
BASIC COMPONENTS OF THE DIGITAL BUSINESS: CRUTOCURRENCY, BLOCKCHAIN, CLOUD TECHNOLOGIES AND INTERNET OF THINGS
}

Yazarlar (Authors): Vagif Gasimov Alijevad®, Shahla Aliyeva

Bu makaleye şu şekilde atıfta bulunabilirsiniz (To cite to this article): Alijevad V.G., Aliyevab S." Basic Componenets of the Digital Business: Crutocurrencty Blockchain cloud Technologies and internet of things ", Int. J. of 3D Printing Tech. Dig. Ind., 4(2): 97-105, (2020). 


\title{
BASIC COMPONENTS OF THE DIGITAL BUSINESS: CRUTOCURRENCY, BLOCKCHAIN, CLOUD TECHNOLOGIES AND INTERNET OF THINGS
}

\author{
Vagif Gasimov Alijavad $^{\text {a }}$ *, Shahla Aliyevab ${ }^{\mathrm{b}}$ iD \\ ${ }^{\mathrm{a}, \mathrm{b}}$ Azerbaijan Technical University, Department of “Computer systems and network", Azerbaijan \\ ${ }^{* *}$ Corresponding Author: gasumov@yahoo.com
}

(Received: 09.05.2020; Revised: 08.06.2020; Accepted: 07.08.2020)

\begin{abstract}
The article is devoted to the investigation of the main components of the digital business, including the digital economy. Also in the article the current state, prospects for the development and application of cryptocurrencies, blockchain, cloud technologies and the Internet of things are analysed. The inevitability of implementation and application of these technologies everywhere during the Fourth Industrial Revolution (Industry 4.0) is noted. Based on this, the possibilities and advantages of these technologies for the implementation of digital business are investigated. In the article the cybersecurity issues arising from the implementation and application of cryptocurrencies, blockchain, cloud technologies and the Internet of things are discussed.
\end{abstract}

Keywords: Digital Economy, Digital Industry, Crutocurrency, Blockchain, Cloud Technologies, Internet of Things.

\section{INTRODUCTION}

Modern information technologies play an important role in the formation of new trends of development of society and the state, new economic outlooks. In the modern globalized world, the importance of the digital economy is growing. Important projects being implemented in this area have a positive impact on economic globalization, and digitization and the growth of online services further enhance the transition to the information society. This requires first of all proper application of new technologies in the digital economy and digital business, building the technological foundation, i.e. basis, of the economy in line with modern standards and the development of innovative technological platforms.

The emergence of new, significantly expanded and automated interconnected forms of information activity of economic entities has created the notion of digital economy and digital business. Changes in the information infrastructure of economic entities due to the development of hardware and software of data processing and transfer technologies have enabled the application of new business models.

Under the digital economy we can understand the economic and financial activities that use digital technology. The digital economy is a system of economic and socio-cultural relations based on the use of digital information and communication technologies. The digital economy is a set of social relations that developed as a result of the use of digital infrastructures and services, digital technologies for the implementation of these relations, analysis of large amounts of data and forecasting in order to optimize the production, distribution, exchange, consumption and increase the level of socio-economic development of the state [1-3].

For the implementation of the digital economy, a comprehensive digitization of data, technologies for processing, storage and transmission of digital data is required. Currently, the technologies of the digital economy, such as cryptocurrency, blockchain, cloud computing and the Internet of things, without which it is impossible to imagine a digital economy, are widely used everywhere. 
Although cryptocurrencies are not so widely used in practice today, the emergence of the COVID-19 pandemic has forced society everywhere to switch to digital technologies to solve managerial, economic, financial, banking, scientific, educational, social and other issues. Based on this, it is safe to say that in the near future, cryptocurrency and blockchain become an inevitable component of our life. However, today society is not yet fully prepared to switch to these technologies. In other words, not all countries have sufficiently studied and implemented these technologies, i.e. they are not always available for implementation in their activities.

Based on the above, this article discusses the formation of digital economics, explores the main components of the digital economy: cloud technology, Internet of things, smart technology, blockchain technology, cryptocurrency. It also explores the possibilities and applications of these technologies, and cybersecurity issues.

\section{BASIC COMPONENTS OF THE DIGITAL BUSINESS}

Today, the main components and key digital technologies of the digital economy are digitization technology, Big Data technology, cloud technology, Internet of things, blockchain technology, cryptocurrency, 3D printers, security tools for cybernetic systems and hardware and software with developed artificial intelligence and neural technologies (Figure 1).

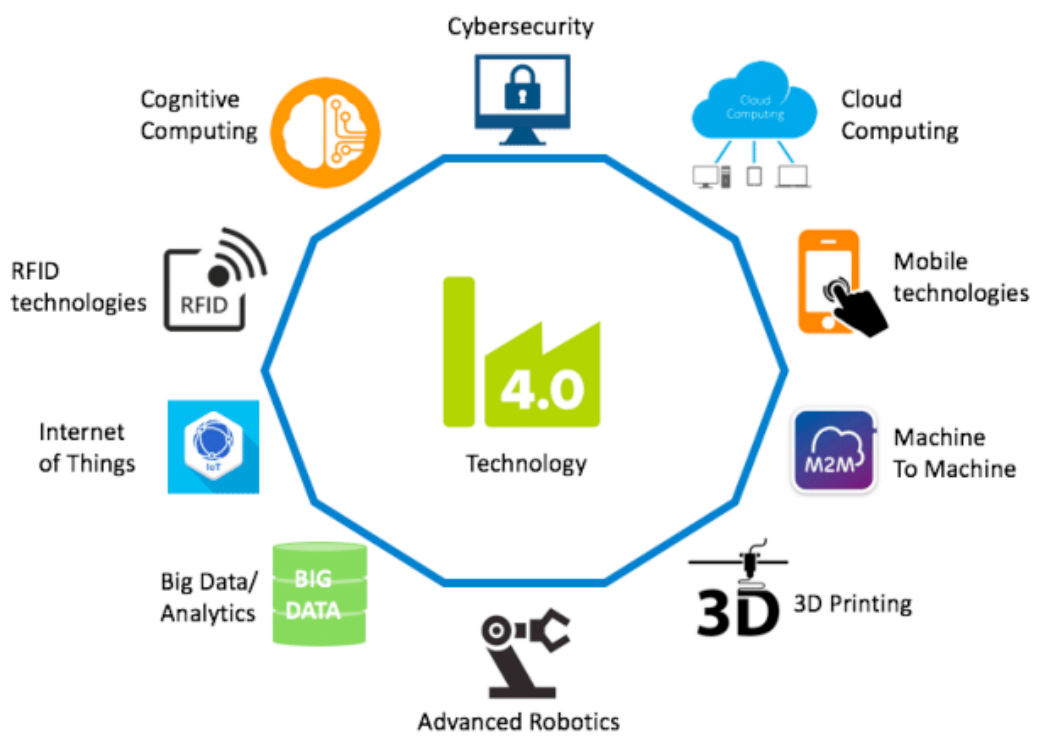

Figure 1. Technologies for industry 4.0

As noted, one of the components of the digital economy is the digitization of all socio-economic and social life, including the economy. Digitization provides a number of advantages, such as: reachability of information by the consumer, improvement of the economic process, the possibility of constant work with clients through the network, and improvement of interaction with consumers via the Internet. Digitization allows you to free employees from routine constantly repeatable operations, remove obstacles, including bureaucracy in the implementation of economic, entrepreneurial activity. The use of new financial technologies expands the ability of enterprises to carry out activities on a global scale.

The second important component of the digital economy is the blockchain technology, which represents the basis for the use of computer and network technologies, including Internet technologies for the formation and development of the digital economy. Blockchain is a multifunctional and multilevel information technology designed for reliable accounting of various assets. Blockchain as a perpetual digital distributed journal of economic transactions, which can be programmed for almost everything that has value. Blockchain technology was first implemented thanks to cryptocurrency 
technology (more precisely, bitcoin), which is also one of the important components of the future of the digital economy $[4,5]$.

As noted above, a blockchain technology is a chain of interconnected data blocks distributed over a network. So, blockchain technology is the use of a combination of methods and means of distributed processing and decentralized data management, the transfer of part of the authority to an organized network community. Moreover, the decision is made by the whole community, and not its separate part, which increases the transparency of the system and the confidence of its participants in the actions of the system.

In other words, blockchain technology is a decentralized electronic chain of blocks arranged in chronological order with a huge digital information array. It should be noted that this data is not stored on the same server, it is stored and processed on many remote and interconnected computers that make up the blockchain technology chain. It is impossible to change data in one block or insert new data block between existing blocks, since if you change one block, you must make the corresponding changes in all blocks of the system, which consists of hundreds of thousands of computers located not only in different cities, but also in different countries.

When making any new transaction, it is confirmed and transformed into a new block of the existing chain. Like any existing block, the new block should also contain complete information about the entire network as a whole. And this excludes the possibility of adding a fake block and changing an existing block, since this requires changes to be made in the entire chain of data blocks. When conducting transactions between two parties, blockchain technology excludes intermediaries (third parties).

For this purpose, blockchain systems use mathematical methods to describe the basic rules for storing and distributing data, while blocks containing digital data are cryptographically encrypted and linked in a chronological order. The blockchain system does not have a single server and administrator, it is independent of external control and impact, and therefore unmanageable. Since each block contains a unique digital signature that captures the transaction, but does not open its contents. Distribution of the database of the blockchain system enhances its protection against hacker attacks, as well as the inability to convert data from a hash, increases security and privacy.

The main advantages of blockchain technology are: trust in the algorithm, decentralization of the system, data immutability, lack of intermediaries between participants, system transparency.

Currently, the blockchain technology is beyond the scope of cryptocurrency technology and is widely used in various fields. Based on the advantages and features noted above, banking and commercial structures, the organization of cybersecurity, government agencies, election commissions, legal and medical organizations, etc. were interested in blockchain technology and began to use it in their activities. In banking, blockchain technology is a clearly structured database of sequentially distributed data in chronological order on different computers with specific rules for constructing transaction chains and access to information.

The term "cryptocurrency" was first used in 2009 with the advent of the Bitcoin payment system. After Bitcoin, a large number of other electronic money appeared, but still not everyone understands what it is, why it attracts so much attention, and how it works [6,7].

Today, there are more than a dozen large cryptocurrencies used around the world. The most popular among these currencies is Bitcoin. Economic forecasts for this market today are more positive. Experts note that the number of cryptocurrencies will continue to grow.

Currently, cryptocurrencies are becoming one of the key factors in the competitiveness of large players in the national and world monetary and financial markets. Digital money exists only in a 
virtual format, it does not have a physical equivalent in the real world. Cryptocurrency is a selfregulatory technology and does not need intermediary services of banking and financial authorities.

The main features and advantages of cryptocurrencies as one of the main factors in the future of the digital economy: infinity; the possibility of financial control; security; lower costs; availability.

With the rapid growth of digital business, cryptocurrency is considered a bright future for our world, and as a result, more and more businesses are beginning to use this currency in their digital businesses. Given the impact of cryptocurrency on the global economy, PayPal, Microsoft, Tesla and others large companies have already begun to benefit this opportunity as a payment option.

According to experts, the cryptocurrency business will continue to grow and influence the processes around the world. Therefore, the sooner businesses enter into their digital business, the higher their chances of entering the new world economy. Moreover, as we have already mentioned, many of the world's leading companies have already adopted it.

The idea behind digital business and cryptocurrency is to create a new economy. Cryptocurrency and blockchain technology provide new opportunities as basic components of the future of the digital economy. Cryptocurrencies add value and usefulness, and the blockchain provides the reliability and security of the digital economy and the global financial market as a whole.

Cloud technology, which is based on computing services such as infrastructure services and cloud platforms, plays an essential part in this revolution. Cloud technology is a technology we use every day through services like Dropbox, Google Drive, and iCloud. Cloud technology widely used in different areas meet current needs in the corporate sector with innovative solutions. The cloud computing trend gives different advantages to the business environment to increase digital productivity and facilitate e-business. Cloud technology potentially provides businesses of all sizes great opportunities to gain substantial benefits, such as increased flexibility, availability of online services, sustainability, accessibility and other [8,9].

With the increasing use of modern technologies, the market economy is continuing to grow more and more rapidly, and accordingly, so are trade and competition. Any failure to provide customer service in this area, however short-term, causes a loss of confidence that it is not easy to compensate for in modern competitive environment. For this purpose, businesses must continuously invest in the sustainability, convenience and security of their systems.

Low initial investment costs are not the only reason for choosing cloud technology. Widening the scope and area of activities results in an increase in the size of databases, additional unforeseen costs and other needs. Therefore, small and medium-sized enterprises understand that switching to cloud technology is more advantageous for such reasons as reduction of primary production costs, maximum results with minimum risk, facilitation of management, natural disaster preparedness, and so on. The reasons behind expanding online shopping are proportional to the reasons behind the growth of cloud technology. Providing an easy-to-use, flexible and reliable environment can enhance customer consistency and satisfaction [10].

Cloud technology is a system that provides software or hardware support services available via local or global network. This technology allows the user to use a convenient interface for remote access to computing, software and data resources. In this case, the user's mobile device only serves as a simple terminal connected to the network. The data is stored in distributed databases located in a virtual environment and called "cloud". For the user, it is a big virtual server. Physically, these servers are located far from each other.

We can distinguish two possible approaches to the use of cloud technology:

- creating a company's own corporate cloud;

- use of existing clouds provided by other, larger companies on a rental basis.

Both approaches have their advantages and shortcomings [11]. 
Companies creating their own corporate clouds eliminates dependence on other organizations and provides solutions to information security issues. However, this requires additional costs (material, technical, personnel, etc.) from the enterprise.

When using existing clouds on a rental basis, one encounters such problems as acquiring new software and hardware, regular updates, ensuring information security, etc. that need to be solved. In this case, all of the enterprise's data is stored on data center servers and the enterprise may use several data centers to ensure their security. It is possible to connect to the program from anywhere and with any device. The servers in data centers are serviced by professionals. Besides, there is no need to purchase and maintain the servers. The user pays only to use the server for storing and working with the data. There is no need for costs such as maintenance, rent, security of special server rooms, training of relevant specialists, salaries, etc. [12].

The shortcomings of this approach are the need for fast and constant Internet access, limited software capacity, tailoring directly to the needs of the enterprise's activity, storage of enterprise-related data in another location, data transmission via open network, etc.

Even companies with little experience in the field of cloud services can easily such clouds. These services allow not only storing and backing up data, but also transferring websites and applications to the cloud, turning them into a multi-level environment. Another advantage of cloud technology is that it is always accessible to the user. Every time you visit a shopping site, the platform offers products and services based on previous user searches, making the application easier to use. Easy use of cloud platforms already supports the provision of services with flexible and secure options. All companies beside companies that develop their own digital transformation style can solve the storage problem with the help of the cloud.

Cloud-based digital services are currently provided to individuals and organizations by certain companies around the world and in our country. Organizations can easily build their activity in a digital environment, provide services in this area and receive technical support from a service provider based on a mutual service agreement without the need for additional workforce.

The main features of cloud-based digital transformation are shown in Figure 2 [13].

One of the important issues that a company should focus on in the selling process is the availability of a reliable digital transformation infrastructure. Reliable infrastructure of cloud-based digital transformation systems and the site information security are provided by the service provider. Thus, customers are able to easily shop on a site that offers digital transformation services.

Due to different payment systems, cloud-based digital transformation systems offer multiple payment methods to site customers during the order stage. The ability to integrate the site with all banking infrastructures and alternative payment options provide customers with payment convenience.

Due to optimized search engines, constantly evolving and changing updates are pursued and applied to the system. The user is notified of the new issues, overlooked and missed opportunities by a group of specialists.

For enterprises, competition means constant development and efficiency. Cloud Store infrastructure updates itself for this competition by means of constantly developing technologies and provides professional solutions, transferring all accumulated experience to digital transformation software. 


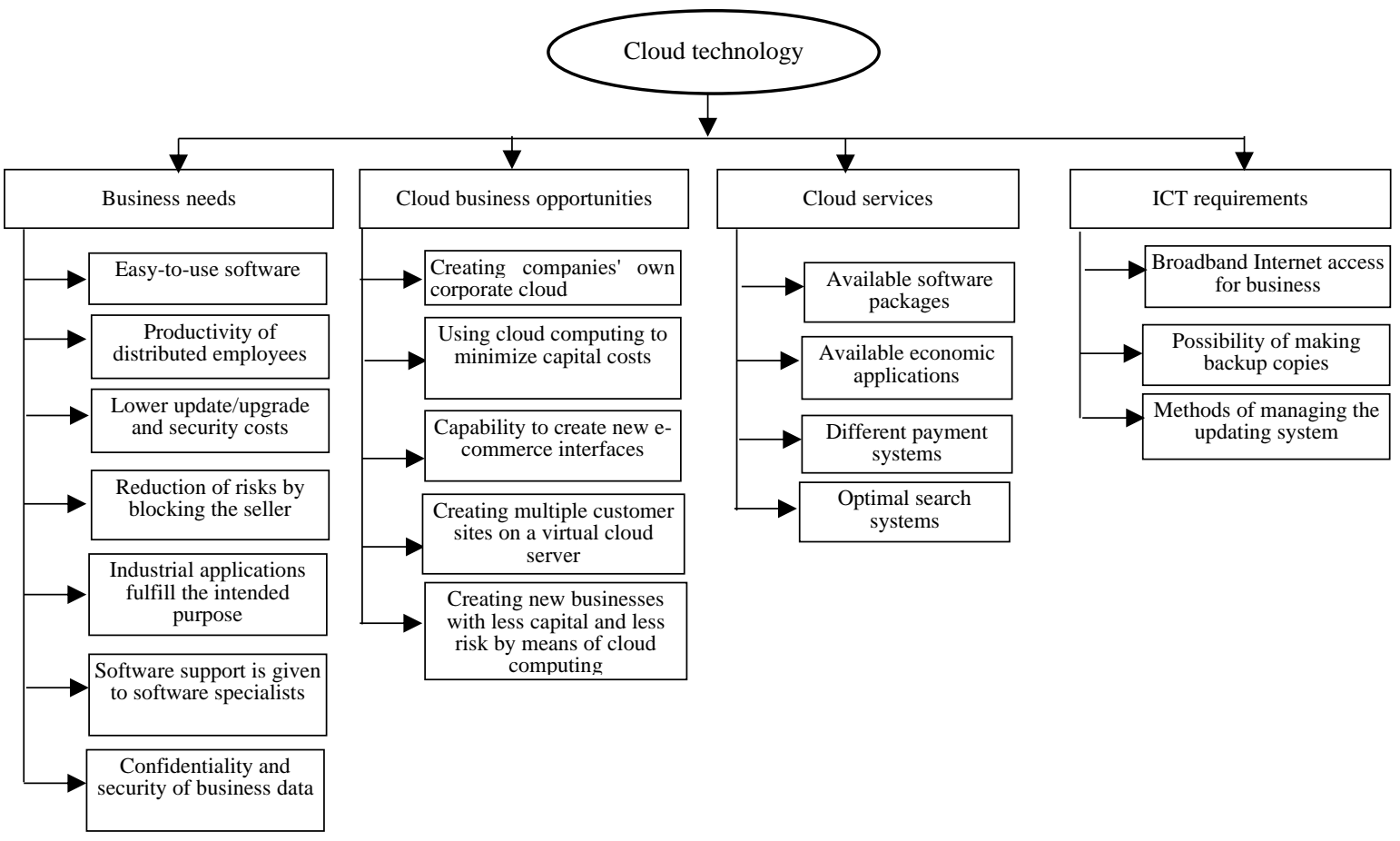

Figure 2. Creating a digital business system using cloud technology

Taking into account the advantages mentioned in the previous paragraphs, large companies around the world are realizing the realities of digitization, focusing on cloud technologies, moving towards digital transformation or upgrading their network infrastructure.

The "ITU Internet Report 2005: The Internet of Things" published by the International Telecommunication Union (ITU) officially presents the concept of the "Internet of Things". The European Union's "Internet of Things: Action Plan for Europe" released in 2009 highlights the importance of this area. The 2011 report by Cisco IBSG (Internet Business Solutions Group) points out that while there were 500 million devices connected to the Internet and 0.08 devices per person in 2003, the figures in 2010 were 12.5 billion and 1.84 per person, respectively. According to experts, these figures will double every 5 years, and by 2020 the world population is expected to increase to 7.6 billion and the number of devices connected to the Internet to 50 billion.

Aside from that, 10 out of 100 people could wear clothes connected to the Internet in 2025 (The Fourth Industrial Revolution, Klaus Schwab), 10 out of 100 pairs of glasses could be connected to the Internet, and 90 out of 100 people in the world population could use smartphones.

The Internet of Things has become a transformation technology for many industries today, creating innovations through new digital and smart manufacturing technologies.

Management via the Internet of devices that people use in their daily lives and activities is a relevant problem. Thus, phones built on modern smart technologies, TV, surveillance cameras, meters, air conditioners, ventilation systems and other devices are items that can be controlled via the Internet. With the use of such devices in everyday activities, entirely new smart products, such as smart home, smart city, etc., appeared.

The Internet of Things technology makes people's lives and activities easier and more advanced. These technologies can save time, increase productivity and even save human lives. It is predicted that in the future, tools providing higher speed data flow between devices and things compared to today will allow producing, using and processing larger volumes of data in the communications environment. 
Areas of use of the Internet of Things technology can be divided into the following categories:

Environmental protection: Internet of Things is used to solve environmental problems such as ecology, clean water, air pollution, solid waste storage and forests protection.

Energy security: Internet of Things contributes to the global energy problem, to the optimization of productivity of products manufacturing clean energy technologies.

Stability and security of society: The Internet of Things participates as an aide to government agencies to increase public security. Devices that allow rapid data exchange between themselves in all areas where a natural disaster happens or medical priority is required are useful in emergencies.

Transport management: Internet of Things is used to create intelligent transport systems that monitor traffic by means of receivers, count vehicles on the roads, calculate traffic times, detect problems on the roads, and calculate duration of parking space use.

Education: In the field of education, technical means, electronic diary, intelligent control and evaluation systems are used.

People's daily and social life: People have started to use Internet of Things technology-based equipment and devices in their daily lives more widely.

The traditional Internet infrastructure connects users via different communication systems. As a result of scientific and technological progress, new technologies are being integrated into the Internet environment through numerous sensor device systems. Sensor devices are used successfully in such areas as monitoring of patients and elderly, tracking traffic flow, security and traffic management through continuous and real-time data flow.

It should be noted that the concept of the Internet of Things owes much of its development to the development of technologies that work sensor devices. Thanks to numerous sensor devices using small cell wireless technologies, it is possible to monitor all your surroundings.

Open cloud services of Internet of Things offer large storage platforms for data processed by devices that make up the Internet of Things, as well as data analysis software (Big Data Analytics) and web services for user interaction. In this regard, Internet of Things has shown a significant impact on the development of specialized cloud services that continuously collect and store data, quick analyzing them and providing them to the user when needed [14].

In digital business, data collected by the Internet of Things system can be used to evaluate employees. Thus, there is a model of automatic evaluation of the effectiveness of intellectual activity of employees in practice. This model uses search engines optimized by companies engaged in digital business or data collected by sensors built on social networks to identify the needs of people in different types of business activities. Despite the development of new intelligent algorithms and methods based on the automated evaluation model, serious problems such as data confidentiality and security remain unresolved.

Thanks to monitoring and control, big data and business analytics, data sharing and collaboration, the Internet of Things contributes significantly to improving customer value. Real-time surveillance and monitoring by means of the Internet of Things allows getting information on issues such as the productivity of research facilities, energy consumption anywhere and at any time. The obtained knowledge makes it possible to identify potential areas of improvement, reduce costs for products and services, and optimize them through increased efficiency. 
The surveillance and monitoring function performed by means of the Internet of Things technology allows offering different values to customers. For instance, in the smart home application concept, the cost of energy savings and security can be determined based on the customer's proposal. This, in turn, helps marketing managers to make certain decisions and to determine marketing strategies of companies. For example, when using a smart home by means of the Internet of Things, a homeowner's smartphone receives a message that a light bulb needs to be replaced or that its expiration date is approaching. In addition, this information can also be sent to the light bulb manufacturer. At the same time, the company focuses on the flaws of its light bulbs and works to improve the quality of its products to enhance customer satisfaction.

In addition to the advantages offered by the Internet of Things, there are also various drawbacks. One and most significant of these drawbacks is the possibility of compromised information security. Security concerns include such issues as data confidentiality, integrity, data integrity protection, ensuring service stability, access control and prevention of intrusions.

\section{CONCLUSION}

The analysis shows that in the near future, the entire society will switch to a digital economy. As we have seen, the COVID-19 pandemic forced the global community to immediately switch to digital business. And this makes you think about methods and technologies for developing, applying and exploiting such new areas as crutocurrency, blockchain, cloud technologies and internet of things, etc., which are the main components of the digital economy. Based on the idea that the digital economy is the basis of digital business, the paper considers the above technologies and analyzes the possibilities of their implementation, as well as the requirements imposed by them in this case.

\section{REFERENCES}

1. Nesterenko E.A., Kozlova A.S. "Направления развития цифровой экономики и цифровых технологий в России] [Directions for the development of the digital economy and digital technologies in Russia" [article in Russian], "Economic security and quality" scientific and practical journal, No. 2 (31), Pages 9$14,2018$.

2. Allahverdiyev F. "Dördüncü sənaye inqilabı (4.0 Sənayesi): Azərbaycan üçün perspektivlər " [The Fourth Industrial Revolution (Industry 4.0): Perspectives for Azerbaijan] [article in Azeri], https://az.trend.az/business/it/2985579.html June 1, 2020.

3. Viktorova N.G., Shukhov F.G. “Цифровая экономика: развитие облачных технологий в России и за рубежом" [Digital economy: development of cloud technologies in Russia and abroad] [article in Russian],, Electronic scientific journal "Century of quality", №2, Pages 81-90, 2019.

4. Nurmukhametov R.K., Stepanov P.D., Novikova T.R. “Технология блокчейн и ее применение в торговом финансировании" [Blockchain technology and its applying in trade finance] [article in Russian], Financial Analytics: Science and Experience, Vol. 11, iss. 2, pp. 179-190, 2018.

5. Fedotov V.V., Emelyanov B.G., Tipner L.M. "The concept of blockchain and the possibility of its use", European science, No. 1 (33), Pages 40-48, 2018.

6. Anokhin N.V., Shmyreva A.I. "Cryptocurrency as an instrument of the financial market", Ideas and ideals, No. 3, Vol. 2, Pages 39-49, 2018.

7. Ageev A.I. "Cryptocurrencies, markets and institutions", Economy Strategies, Moscow, Vol. 20, No. 1, Pages 94-107, 2018.

8. Makhmudov R.Sh. "Bulud texnologiyası iqtisadiyyatının mövcud vəziyyətinin təhlili və inkişaf perspektivlori“" [Analysis of the current state and prospects for the development of the cloud technology economy] [article in Azeri], Problems of the information, №2, Pages 14-23, 2014.

9. “Cloud Computing and Digital Marketing”, https://xcluesiv.com/cloud-computing-and-digitalmarketing.html, June 1, 2020. 
10. "David Wicks. Impacts of Cloud Computing in Online Marketing", http://digital marketing magazine.co.uk/digital-marketing-features/impacts-of-cloud-computing-in-online-marketing, June 1, 2020.

11. Konstantinos K. and etc. "Cloud computing and economic growth", https://www.researchgate.net/ publication/282573827_Cloud_computing_and_economic_growth, June 1, 2020.

12. "The Ultimate Guide to Digital Marketing", https://www.digitalmarketer.com/digitalmarketing/assets/pdf/ultimate-guide-to-digital-marketing.pdf, June 1, 2020.

13. “Cloud Computing Overview Map", https://www.matthewb.id.au/computer/Cloud-ComputingOverview.html , June 1, 2020.

14. Gasimov V.A., Amashov Y.A. “Oşyaların İnterneti kibertəhlükəsizliyə yeni təhlükə kimi” [The Internet of things as a new threat to cybersecurity] [article in Azeri], Materials of the II Scientific and Practical Conference of Youth with International Participation. National Aviation Academy of Azerbaijan Republic, Pages 69-71, Baku, 21-23 February 2017. 